\title{
Bazı toprak kökenli funguslara karșı defne esansiyel yağı ve hidrosölünün antifungal etkilerinin belirlenmesi*
}

\author{
Muharrem TÜRKKAN ${ }^{\circledR 1}$, Ömer ÇALIŞKAN ${ }^{\circledR 2}$, İsmail ERPER ${ }^{\circledR 3,4}$, Ș. Metin KARA ${ }^{\circledR}$, M. Akif AÇIKGÖZ ${ }^{\circledR}$ \\ ${ }^{1}$ Ordu Üniversitesi, Ziraat Fakültesi, Bitki Koruma Bölümü, 52200, Altınordu/Ordu \\ 20ndokuz Mayıs Üniversitesi, Bafra Meslek Yüksekokulu, Bitkisel ve Hayvansal Üretim Bölümü, 55400 Bafra/Samsun \\ ${ }^{3}$ Ondokuz Mayıs Üniversitesi, Ziraat Fakültesi, Bitki Koruma Bölümü, 55139 Atakum/Samsun \\ ${ }^{4}$ Kırgızistan-Türkiye Manas Üniversitesi, Ziraat Fakültesi, Bitki Koruma Bölümü, 720044 Bişkek/Kırgızistan \\ 50rdu Üniversitesi, Ziraat Fakültesi, Tarla Bitkileri Bölümü, 52200, Altınordu/ Ordu
}

*Bu çalıșma Ordu Üniversitesi Bilimsel Araștırma Projeleri tarafından desteklenmiștir (Proje No: AR-1330)

Alınış tarihi: 30 Ekim 2018, Kabul tarihi: 2 Ocak 2019

Sorumlu yazar: Muharrem TÜRKKAN, e-posta:muharremturkkan@odu.edu.tr

Öz

Mevcut çalışmada, defne (Laurus nobilis L.) uçucu yağının ve hidrosölünün Fusarium oxysporum f. sp. cepae, Rhizoctonia solani AG-4, Macrophomina phaseolina ve Sclerotium rolfsii'ye karșı antifungal etkileri in vitro ve toprak test yöntemleri kullanılarak değerlendirilmiștir. Ayrıca uçucu yağın kimyasal bileşenleri GC-MS analizleri ile belirlenmiștir. Ana bileșeni 1,8-sineol (\%57.03) olan defne uçucu yağında on altı bileșen tespit edilmiştir. Miselyal gelişme, spor çimlenmesi ve sklerot çimlenmesi dahil olmak üzere tüm in vitro çalışmalarda, uçucu yağın dört fungusun tamamına karşı engelleyici etkisi, uçucu yağ hidrosölününkünden çok daha yüksek olduğu tespit edilmiştir. Ayrıca, F. oxysporum f. sp. cepae, M. phaseolina, $R$. solani AG-4 ve $S$. rolfsii için uçucu yağın $\mathrm{EC}_{50}$, MIC ve MFC değerleri sırasıyla $9.84,>40$ ve $>40,5.28,>40$ ve $>40,3.55,20$ ve $>40$, ve $2.74,20$ ve $40 \mu \mathrm{l} /$ petri olarak belirlenmiştir. Toprak testlerinde, uçucu yağ ( $40 \mu \mathrm{L} /$ petri) $R$. solani AG-4 ve $S$. rolfsii'nin misel gelişimini tamamen engellemiş, ancak $F$. oxysporum f. sp. cepae ve M. phaseolina'nı misel gelişimini sırasıyla \%63.61 ve \%95.53'e kadar azaltmıștır. Bununla birlikte, uçucu yağın birinci grup funguslara karşı engelleyici etkisi ile $M$. phaseolina'nınki arasındaki fark istatistiksel olarak önemli bulunmamıștır. Uçucu yağ hidrosölünün en yüksek konsantrasyonu $(\% 40$, w/v)'nda bile, $F$. oxysporum f. sp. cepae, M. phaseolina, R. solani AG-4 ve $S$. rolfsii'nin misel gelișmelerini sırasıyla \%2.91, 5.36, 26.80 ve 35.13'e kadar azaltmıştır. Bu çalışmanın sonuçları, çeşitli toprak kökenli fungusların kontrolünde defne uçucu yağının kullanılabileceğini göstermektedir.

Anahtar kelimeler: Defne, uçucu yağ, toprak kökenli funguslar, alternatif kontrol

Determination of antifungal effects of laurel essential oil and hydrosol against some soilborne fungi

\footnotetext{
Abstract

In present study, the antifungal activities of the essential oil and hydrosol of laurel (Laurus nobilis L.) against Fusarium oxysporum f. sp. cepae, Rhizoctonia solani AG-4, Macrophomina phaseolina and Sclerotium rolfsii were evalualted by using in vitro and soil test methods. The chemical composition of the essential oil were also determined by GC-MS analysis. Sixteen components were detected in the essential oil, the main component of which was 1,8cineole $(57.03 \%)$. In all in vitro studies, including mycelial growth, spore germination, and sclerotial germination, the inhibitory effect of the essential oil against all four fungi was found to be much higher than that of the essential oil hydrosol. In addition, the values of $\mathrm{EC}_{50}$, MIC and MFC of the essential oil for $F$. oxysporum f. sp. cepae, M. phaseolina, R. solani AG-4 and S. rolfsii were 9.84, >40 and >40, 5.28, >40
} 
and $>40,3.55,20$ and $>40$, and 2.74, 20 and 40 $\mu \mathrm{l} /$ petri, respectively. In soil tests, the essential oil (40 $\mu \mathrm{L} /$ petri) completely inhibited the mycelial growth of $R$. solani AG-4 and $S$. rolfsii, but reduced the mycelial growth of $F$. oxysporum f. sp. cepae and M. phaseolina by 63.61 and $95.53 \%$, respectively. However, the difference between the inhibitory effect of the essential oil against the first group fungi, and that of $M$. phaseolina was not statistically significant. Even at the highest concentration (40\%, $\mathrm{w} / \mathrm{v}$ ) of the essential oil hydrosol, it reduced the mycelial growth of $F$. oxysporum f. sp. cepae, $M$. phaseolina, R. solani AG-4 and S. rolfsii by 2.91, 5.36, 26.80 and $35.13 \%$, respectively. The results of this study show that the essential oil of laurel could be used in the control of various soilborne fungi.

Key words: Laurel, essential oil, soilborne fungi, alternative control

\section{Giriş}

Toprak kökenli fungal patojenler, tarla ve bahçe bitkilerinde sıklıkla ölümle sonuçlanan ve önemli verim kayıplarına yol açan kök çürüklüğü hastalık kompleksinin gelişiminde büyük bir rol oynarlar (Siddiqui et al., 2002). Fusarium, Rhizoctonia, Macrophomina ve Sclerotium cinsleri bitkilerde vasküler solgunluk, kök ve gövde çürüklükleri, çökerten ve yanıklıklara neden olan önemli toprak kökenli fungal patojenlerdir (Agrios, 2005).

$\mathrm{Bu}$ hastalıklar ile mücadelede sağlıklı üretim materyali kullanılması, topraktaki fazla suyun drene edilmesi, enfekteli bitki artıklarının alandan uzaklaştırılması, dengeli gübreleme ve sulama gibi kültürel önlemler, bitkisel materyallerin sıcak su ile muamele edilmesi ve toprak solarizasyonu gibi fiziksel önlemler, dayanıklı bitki çeşitlerinin yetiştirilmesi, topraktaki faydalı mikroorganizma (bakteri, fungus vd.)'ları harekete geçirmek için toprağın organik materyaller ile zenginleștirilmesi ve arbuskular mikorhizal uygulamaları gibi biyolojik önlemlerin yanı sıra tohumların fungisit (benomil, captan, carbendazim ve thiram vd.)'ler ile muamelesi ve toprak fumigasyonu (metil bromid, metam sodyum ve dazomet) gibi kimyasal savaşım yöntemleri tavsiye edilmektedir (Farih et al., 1981; Yuen et al., 1991; Duniway, 2002; Agrios, 2005; Alaniz et al., 2011). Ancak bu hastalık etmenleri ile mücadele, toprakta uzun yllar canlılıklarını koruyabildikleri dayanıklı yapıları (klamidospor, sklerot vd.)'nın olması, direnç sorunları ve kullanılan fungusitlerin maliyetlerinin yüksekliği nedeniyle oldukça zordur (Yangui et al., 2008). Ayrıca günümüzde bu etmenlere karşı mücadelede en etkili olan kimi fungisitler (benomil, carbendazim, metil bromid) hem dünyada hem de ülkemizde yasaklanmıştır (Fan et al., 2008; Anonymous, 2018). Bunlara alternatif olarak kullanılan fungisitlerin yetiştiriciliği yapılan ürünlerde ve toprakta kalıntılara neden olmakta, çevre ve insan sağlığını olumsuz bir şekilde etkilemektedir. Bu yüzden, bitki hastalıkları ile mücadele de yeni stratejiler içerisinde bitkinin gelişme sezonu içerisinde kullanılabilen kimyasal içermeyen doğal bileșiklerle patojenlerin mücadelesinin yapılmasına ihtiyaç duyulmaktadır. Son yıllarda çeşitli tıbbi ve aromatik bitkilerden elde edilen uçucu yağlar bitki hastalıklarının kontrolünde doğal fungisit olarak değerlendirilmektedir (Isman, 2000; Paulitz and Belanger, 2001). Adaçayı, biberiye, defne, güvey otu, karanfil, kekik, kimyon, lavanta, limon otu, mercanköşk, nane, oğul otu, ökaliptus, rezene, sedef otu, tarçın, yavşan otu, yarpuz gibi bitkilerden elde edilen uçucu yağlar hasat öncesi ve hasat sonrası fungal hastalıkların kontrolünde kullanılmıştır (Zambonelli et al., 1996; Wilson et al., 1997; Ristic et al., 2000; Walter et al., 2001; Bouchra et al., 2003; Daferera et al., 2003; Bowers and Locke, 2004; Soylu et al., 2005a; Soylu et al., 2005b; Lee et al., 2007). Uçucu yağların biyolojik aktiviteleri uçucu yağların elde edildiği bitki genotipine ve bitkilerin yetiştiği ekolojik koşullara, test metodlarına ve mikroorganizmaya bağlı olarak oldukça değişkenlik göstermektedir (Giese, 1994; Rota et al., 2004; Yeşil Çeliktaş et al., 2007). Bitki uçucu yağları terpenoidlerin özellikle monoterpen ve sesquiterpenlerin değişken karışımlarından oluşur, ancak bunun yanı sıra bitki uçucu yağlarında diterpenler ve çeşitli düşük molekül ağırlıkta bileşikler (alifatik hidrokarbonlar, asitler, alkol, aldehitler, fenolik bileșikler, asiklik esterler veya laktonlar)'de bulunabilir. Antimikrobiyal etkileri de bu uçucu yağ fraksiyonlarından kaynaklanmaktadır (Rota et al., 2004).

$\mathrm{Bu}$ çalışmada defne (Laurus nobilis L.) yaprağından elde edilen uçucu yağ ve hidrosölünün Fusarium oxysporum f. sp. cepae, Rhizoctonia solani AG-4, Macrophomina phaseolina ve Sclerotium rolfsii'nin misel gelişimi, spor ve sklerot çimlenmesi üzerine etkileri in vitro'da belirlenmiş ve uçucu yağ ve hidrosölünün misel gelişimi üzerine etkileri toprak testleri ile de değerlendirilmiştir. Ayrıca çalışmada defne uçucu yağ bileşimi gaz kromotografi/kütle spektrometresi (GC-MS) ile belirlenmiştir. 


\section{Materyal ve Yöntem}

\section{Fungal kültür}

Çalışmada kullanılan toprak kökenli fungal [F. oxysporum f. sp. cepae (soğan), $R$. solani AG-4 (soğan), M. phaseolina (fasulye) ve $S$. rolfsii (fasulye)] izolatlar Ordu Üniversitesi Ziraat Fakültesi Bitki Koruma Bölümü Fitopatoloji Laboratuvarı'ndaki fungal kültür koleksiyonundan temin edilmiştir.

\section{Bitkisel materyal}

Çalışmada kullanılan defne (Laurus nobilis L.) yaprakları 2014 yılında Samsun ili Bafra ilçesinden toplanmıştır.

\section{Defne uçucu yağlarının eldesi}

Defne yaprakları (2 kg) gölgede 3-4 hafta kurutulup küçük parçalara ayrıldıktan sonra 500 mL'lik cam balonlara alınmış ve üzerine bir miktar su ilave edilip cam balonlar elektrikli isitıcıya yerleștirilmiștir. Cam balonun ağzına soğutucu bağlı Klevenger aparatı cihazın büret kısmında uçucu yağ miktarında değişim olmayıncaya kadar 4-5 saat süre ile isıtılmıştır. Bu şekilde buhar distilasyonu ile elde edilen uçucu yağlar $0.22 \mu \mathrm{m}$ porluk membran filtrelerden geçirilerek sterilize edilmiştir (Çakır, 1992). Çalışmada elde edilen defne yağ hidrosölü de membran filtrelerden geçirilerek sterilize edilmiştir. Elde edilen uçucu yağlar denemelerde kullanılıncaya kadar $+4^{\circ} \mathrm{C}^{\prime}$ de içerisinde anhydrous sodium sulphate bulunan vida kapaklı koyu renkli cam şişelerde saklanmıştır.

\section{Defne uçucu yă bileşenlerinin gaz kromotografi/kütle spektrometresi (GC-MS) ile belirlenmesi}

Defne uçucu yağ bileşenlerinin GC-MS analizi Çankırı Karatekin Üniversitesi Merkez Araştırma Laboratuvarı'ndan hizmet alımıla yapılmıștır. Bileşen analizleri, otomatik örnekleyici sistemi bulunan 7890 A model GC system, 5975C inert MSD with Triple-Axis Detector ile gerçekleştirilmiştir. Örnekler 1:10 oranında hekzan ile seyreltilerek bileşenlerin ayrımı için HP-5 (\%5 Phenyl Methyl Siloxan) $1 \mu \mathrm{L}$ olarak split (10:1) modunda enjekte edilmiştir. Taşıyıcı gaz olarak kullanılan helyumun iç basıncı 5 psi olarak ayarlanmıştır. Enjektör sıcaklığı $250^{\circ} \mathrm{C}$, detektör sıcaklığı $250^{\circ} \mathrm{C}$ olacak şekilde planlanmıştır. Kolonun başlangıç sıcaklığı $60^{\circ} \mathrm{C}$, son sıcaklığı $240^{\circ} \mathrm{C}$ olup, dakikada $4^{\circ} \mathrm{C}$ artacak şekilde programlanmıştır. GC/MS ayırımı için, $70 \mathrm{eV}$ iyonizasyon enerjili, elektron iyonizasyon sistemi kullanılmıştır. Taşıyıcı gaz olarak kullanılan helyumun akış oranı $1 \mathrm{~mL} / \mathrm{dk}$. ve kullanılan kolon ise
HP-5Ms ( $30 \mathrm{~m} \times 0.25 \mathrm{~mm} \times 0.25 \mu \mathrm{m}$ film) dir. Enjektör ve MS transfer sicaklıkları sirasıyla $230^{\circ} \mathrm{C}$ ve $250^{\circ} \mathrm{C}$ olacak şekilde ayarlanmıştır. Gaz kromotografisinde olduğu gibi, hekzan ile seyreltilen örnekten $1.0 \mu \mathrm{L}$ split/splitles (10:1) olarak kolona verilmiştir (McLafferty, 1994; Adams, 1995).

Misel gelişimi üzerine defne uçucu yağ ve hidrosölünün buhar ve değme etkilerinin belirlenmesi

Defne uçucu yağının fungusların misel gelişimi üzerine buhar etkisini belirlemek için, $9 \mathrm{~cm}$ çapındaki steril petri kaplarına patates dekstroz agar [PDA; Difco Laboratories, Becton Dickinson (BD), Maryland, USA] besin ortamı dökülmüş ve ertesi gün petri kaplarının merkezine 4-7 günlük fungus kültürlerinin diskleri $(5 \mathrm{~mm})$ PDA ile temas edecek şekilde yerleştirilmiştir. Uçucu yağ $(40 \mu \mathrm{L} /$ petri $)$ petri kaplarının kapağının merkezine yerleștirilen steril filtre kağıdına $(10 \mathrm{~mm}$, Whatman No.1) damlatılıp petri kaplarının etrafı parafilm ile kapatıldıktan sonra ters çevrilerek $24 \pm 1^{\circ} \mathrm{C}^{\prime} \mathrm{de}$ inkübasyona bırakılmıștır. Kontrol petri kapaklarına sadece steril saf su damlatılmıştır. Aynı koşullarda inkübe edilen kontrol grubu petrilerdeki fungusların gelișmeleri günlük olarak takip edilerek petriyi kaplamaya yakın olduğunda, kontrol ve uçucu yağ içeren petrilerdeki fungusların misel gelişmeleri dijital kumpas kullanılarak ölçülmüştür.

Defne yağ hidrösölünün fungusların misel gelişimi üzerine değme etkisini belirlemek için, hidrösöl steril edilmiş PDA besin ortamına $\left(50^{\circ} \mathrm{C}\right)$ son konsantrasyonu \%40 (v/v) olacak şekilde eklenmiş ve $9 \mathrm{~cm}$ çapındaki petri kaplarına dökülmüştür. $\mathrm{Bu}$ petriler, daha önceden PDA besin ortaminda geliştirilmiş 4-7 günlük fungus kültürlerinden mantar delici ile alınan $5 \mathrm{~mm}$ çaplı miselyal disklerle inokule edilmiștir. Petriler parafilm ile kaplandıktan sonra $24 \pm 1^{\circ} \mathrm{C}^{\prime}$ de inkübe edilmiștir. Aynı koşullarda inkübe edilen kontrol (steril saf su içeren PDA) grubu petrilerdeki fungusların gelişmeleri günlük olarak izlenerek petriyi kaplamaya yakın olduğunda, kontrol ve uçucu yağ hidrösöllü petrilerdeki fungusların misel gelişmeleri dijital kumpas kullanılarak ölçülmüştür.

Ölçümler sırasında fungusların en uzun ve kısa radyal gelişmeleri esas alınmış ve miselyal gelişmenin engellenmesi Abbot formülü, \% Engelleme $=[$ (kontrol petrilerindeki fungal gelișmeuçucu yă̆ eklenmiş veya steril filtre kağıdına damlatılmış petrilerdeki fungal gelişme) / kontrol petrilerindeki fungal gelişme]*100, kullanılarak 
hesaplanmıştır. Denemede her uygulama 6 tekerrürlü olacak şekilde planlanmıştır.

Misel gelişimi üzerine defne uçucu yağ ve hidrosölünün toksik etkilerinin belirlenmesi

Defne yağ $(2.5,5,10,20$ ve $40 \mu \mathrm{L} /$ petri) ve hidrosöl $\left[\% 5,10,20\right.$ ve $40(\mathrm{v} / \mathrm{v})^{\prime}$ lerinin fungusların miselyal gelişmesini $\% 50$ oranında azaltan konsantrasyon $\left(\mathrm{EC}_{50}=\right.$ lethal concentration)'ları probit (IBM SPSS Statistic 20) analizi ile hesaplanmıștır. Fungus miselyal gelişmelerini tamamen engelleyen en küçük konsantrasyon (MIC $=$ minimum inhibition concentration) değeri paralel denemelerle belirlenmiştir. Defne yağ ve hidrosölünün fungisidal veya fungistatik etkileri Thompson (1989) ve Tripathi et al. (2004)'nin metodları izlenerek belirlenmiştir. Buna göre gelişmeyen fungus diskleri petrilerden alınarak, taze besin ortamı içeren petrilere tekrar aşılanmıştır. Fungusların gelişmeleri $24 \pm 1^{\circ} C^{\prime}$ de 9 gün boyunca gözlenmiştir. Bu sürede zarfında fungal diskte geri dönüşümsüz olarak hiç bir gelişme gözlenmemişse, bu konsantrasyon fungusu tamamen engelleyen konsantrasyon (MFC = minimum fungicidal concentration) olarak belirlenmiştir. Ayrıca aktarılan fungusun tekrar gelişmeye başladığı ve petriyi tamamen kapladığı gün sayısı belirlenerek defne yağ ve hidrosöllerinin konsantrasyonlarının fungistatik etkileri de belirlenmiştir.

\section{Spor çimlenmesi üzerine defne uçucu yağ ve hidrosölünün buhar ve değme etkilerinin belirlenmesi}

Defne yağının F. oxysporum f. sp. cepae spor çimlenmesi üzerine buhar etkilerinin belirlenmesi için, $9 \mathrm{~cm}$ çapındaki steril petri kaplarına PDA besin ortamı dökülmüş ve ortam katılaştıktan sonra, daha önceden hazırlanmış 7 günlük fungus kültürlerine 10 $\mathrm{mL}$ steril saf su [\%0.5 (v/v) Tween-20] eklenerek steril bir bistürü yardımıyla kültürün yüzeyi kazınmış ve elde edilen süspansiyon 3 katlı steril tülbentten geçirilmiştir. $\mathrm{Bu}$ şekilde hazırlanan spor süspansiyonu ( $1 \times 10^{4}$ spor $\left./ \mathrm{mL}\right)$ PDA besin ortamına yayılarak, uçucu yağın farklı $(2.5,5,10,20$ ve 40 $\mu \mathrm{L} /$ petri) konsantrasyonları petri kaplarının merkezine yerleştirilen steril filtre kağıdına damlatılıp, petri kaplarının etrafı parafilm ile kapatıldıktan sonra ters çevrilerek $24 \pm 1^{\circ} \mathrm{C}$ 'de inkübasyona bırakılmıştır. Kontrol grubu petri kaplarına sadece steril saf su damlatılmış ve aynı koşullarda inkübasyona bırakılmıștır. Spor çimlenmesi için değerlendirme 24 saat sonra yapılmıştır. Deneme üç tekerrürlü olarak yürütülmüş ve her petride iki farklı alanda 100'er spor sayılmıştır.

Defne yağ hidrosölünün $F$. oxysporum f. sp. cepae spor çimlenmesi üzerine değme etkisinin belirlenmesi için yağ hidrosölünün son konsantrasyonları $\% 5,10,20$ ve 40 olacak şekilde steril edilip soğutulmuş PDA besin $\left(50^{\circ} \mathrm{C}\right)$ ortamına eklenmiş ve $9 \mathrm{~cm}$ çapındaki steril petri kaplarına dökülmüştür. Yukarıda belirtildiği şekilde hazırlanan spor süspansiyonu yağ hidrosöllü PDA besin ortamına yaylarak, $24 \pm 1^{\circ} \mathrm{C}$ 'de inkübasyona bırakılmıştır. Uygulama yapılmamış petri kapları kontrol grubu olarak kullanılmıştır. Değerlendirme yukarıda belirtildiği şekilde yapılmıştır.

Sklerot çimlenmesi üzerine defne uçucu yağ ve hidrosölünün buhar ve değme etkilerinin belirlenmesi

Defne yağının sklerot çimlenmesi üzerine buhar etkisini belirlemek için $S$ rolfsii'nin saf kültürlerinden elde edilen (3-4 haftalık fungus kültürü) sklerotlar, PDA besin ortamı dökülmüş $9 \mathrm{~cm}$ çapındaki petri kaplarına 5'er adet olacak şekilde yerleștirilmiş ve petri kaplarının kapaklarının merkezine yapıştırılan steril filtre kağıtlarına uçucu yağların yukarıda belirtilen konsantrasyonları damlatılmıștır. Daha sonra petri kapları parafilm ile kapatılarak ve $24 \pm 1^{\circ} \mathrm{C}$ 'de inkübasyona bırakılmıștır. Deneme 5 tekerrürlü olacak şekilde yürütülmüştür. Değerlendirmelerde kontrol grubu (steril safsu) petri kaplarındaki sklerotların çimlenme durumları takip edilerek, uçucu yağ uygulaması yapılmış petrilerdeki sklerotların çimlenme oranları buna göre \% olarak belirlenmiştir.

Defne yağ hidrosölünün sklerot çimlenmesi üzerine değme etkisinin belirlenmesi için, yukarıda belirtildiği şekilde hazırlanan petri kaplarına $S$. rolfsii'nin 5'er adet sklerotu eşit aralıklarla yerleștirilmiștir. Değerlendirme yukarıda belirtildiği şekilde yapılmıştır.

Toprak testleri ile defne uçucu yağ ve hidrosölünün funguslar üzerine buhar ve değme etkilerinin belirlenmesi

Defne yağ ve hidrosölünün etkilerini değerlendirmek amaciyla toprak testlerinde Arslan et al. (2009) tarafından tanımlanan metod biraz değiştirilerek kullanılmıştır. Mısır unu-kum ortamında, kumun mısır ununa oranı 1'e 8 olacak şekilde ayarlanmıştır. Mısır unu kum karışımı ortamın 9 g' 7 cm çapındaki cam petrilere konduktan sonra petri kapları etüvde $130^{\circ} \mathrm{C}^{\prime}$ de 5 saat steril edilmiştir. Daha önce PDA 
besin ortamında geliștirilen 4-7 günlük fungus ( $F$. oxysporum f. sp. cepae, M. phaseolina, R. solani AG-4 ve $S$. rolfsii) kültürlerinden alınan $5 \mathrm{~mm}$ çaplı misel diskleri, misır unu-kum ortamının merkezine 0.25 cm derinliğine yerleştirilmiştir. Fungal diskler petrinin ortasına yerleştirildikten sonra ortamda fungal gelişmeyi sağlamak için birkaç mL steril saf su ilave edilmiştir. Uçucu yağın farklı konsantrasyon (5, 10,20 ve $40 \mu \mathrm{L} /$ petri)'ları petri kapaklarına yerleştirilen steril filtre kağıtlarına damlatılmış ve petri kapları parafilm ile kapatılıp $24 \pm 1^{\circ} \mathrm{C}$ 'de $5-10$ gün karanlıkta inkübasyona bırakılmıștır. Kontrol grubu petri kaplarına ise steril saf su eklenmiştir. İnkübasyon sonrasında petri kapakları üzerine $1 \mathrm{~cm}^{2}$ ve $1 \mathrm{~mm}^{2}$ 'lik karelere bölünmüş asetat kağıdı yerleştirilerek fungusların miselyal gelişme alanı ölçülmüştür. Engelleme yüzdesi, uçucu yağın farklı konsantrasyonları eklenmiş petrilerdeki miselyal gelişme ve kontrol grubu kontrol grubu petrilerdeki miselyal gelişme alanı \% engelleme olarak belirlenmiştir. Denemede her uygulama 6 tekerrürlü olacak şekilde yürütülmüştür.

Defne yağ hidrosölünün etkisini belirlemek için, yukarıda belirtildiği şekilde hazırlanan besin ortamının merkezine fungal diskler yerleștirildikten sonra yağ hidrosölünün farklı konsantrasyon (\%10, 20 ve $40, \mathrm{v} / \mathrm{v}$ )'larının 10 'ar $\mathrm{mL}$ si petri ortamına steril cam pipet ile eklenmiş ve petri kapları parafilm ile kapatılıp $24 \pm 1^{\circ} \mathrm{C}^{\prime} \mathrm{de}$ 5-10 gün karanlıkta inkübasyona bırakılmıştır. Kontrol grubu petri kaplarına ise sadece steril saf su ilave edilmiştir. Inkübasyon süresi sonunda fungal gelişme yukarıda belirtildiği şekilde değerlendirilmiştir.

\section{İstatistik analiz}

Fungusların misel, spor ve sklerot çimlenmeleri ile toprak testi sonucu elde edilen veriler ayrı ayrı olacak şekilde IBM SPSS Statistic programı kullanılarak tek yönlü varyans analizi (ANOVA) yapılmış ve ortalamalar arasındaki önemli farklılıklar Tukey-HSD testi $(\mathrm{P}<0.05) \quad$ ile belirlenmiştir.

\section{Bulgular}

Mevcut çalıșmada, GC/MS analizleri ile defne uçucu yağında 16 etken madde belirlenmiștir (Çizelge 1). Bunlardan 1,8-cineole \%57.03'lük oran ile defne uçucu yağ bileşeninde en yüksek oranda olup, bunu terpinyl acetate (\%13.35) izlemiştir.

In vitro denemelerde, $40 \mu \mathrm{L} /$ petri konsantrasyonda, defne yağının buhar etkisi $F$. oxysporum f. sp. cepae ve M. phaeseolina'nın miselyal gelișmelerini sırasıyla
$\% 87.38$ ve $\% 96.06$ azaltırken, $R$. solani AG-4 ve $S$. rolfsii'nin miselyal gelişmesini tamamen engellemiş ve bu fark istatistik olarak da önemli bulunmuştur $(\mathrm{P}<0.05)$. Yă̆ hidrosölü $(\% 40, v / v)$ 'nün funguslar üzerindeki temas etkilerinin daha sinırlı bir etkiye sahip olduğu ve miselyal gelişmelerini \%6.13-56.74 oranında azalttığını göstermiştir.

Defne yağı en yüksek toksisiteyi $S$. rolfsii'ye karşı göstermiștir, bunu sirasiyla $R$. solani AG-4, $M$. phaseolina ve $F$. oxysporum f. sp. cepae izlemiştir (Çizelge 2). İlk iki fungus için MIC değerleri 20 $\mu \mathrm{L} /$ petri iken, $M$. phaseolina ve $F$. oxysporum f. sp. cepae için $>40 \mu \mathrm{L} /$ petri olarak belirlenmiştir. Ancak bu fungusların miselyal gelişmesini durduran bu konsantrasyonun bir üst konsantrasyon (40 $\mu \mathrm{L} /$ petri)'u $S$. rolfsii için fungisidalken, $R$. solani AG-4 için ise fungisitatik etki olarak belirlenmiştir (Çizelge 3). Diğer iki fungus için MFC değeri $>40 \mu \mathrm{L} /$ petri olarak tespit edilmiştir. Yağ hidrosölü fungusların miselyal gelişmelerini nispeten çok zayıf bir şekilde etkilediğinden, $S$. rolfsii'nin $\mathrm{EC}_{50}$ değeri (\%32.69) hariç tüm funguslar için $\mathrm{EC}_{50}$, MIC ve MFC değerleri $\% 40$ 'tan büyük bulunmuştur.

Çizelge 1. Defne uçucu yağının bileşenleri

\begin{tabular}{cccc}
\hline No & Bileşenler & $\begin{array}{c}\text { Allkonma } \\
\text { zamanı }\end{array}$ & $\begin{array}{c}\% \\
\text { Miktar }\end{array}$ \\
\hline 1 & alpha-Pinene & 12.812 & 3.65 \\
2 & $\beta$-Thujene & 14.056 & 5.44 \\
3 & $\beta$-Pinene & 14.260 & 3.18 \\
4 & 1,8-Cineole & 16.078 & 57.03 \\
5 & $\gamma$-Terpinene & 16.918 & 0.92 \\
6 & Linalyl acetate & 18.214 & 0.59 \\
7 & Isopulegol & 20.837 & 0.60 \\
8 & 4-Terpineol & 21.238 & 4.20 \\
9 & $\alpha$-Terpineol & 21.657 & 2.81 \\
10 & Isobornyl formate & 24.915 & 0.64 \\
11 & Pseudolimonen & 25.886 & 0.66 \\
12 & Terpinyl acetate & 26.935 & 13.35 \\
13 & Eugenol & 27.230 & 1.64 \\
14 & Methyleugenol & 28.547 & 3.55 \\
15 & Spathulenol & 34.393 & 0.50 \\
16 & Bicyclo[4.3.0]nonane, 7-methylene- & 34.632 & 1.24 \\
\hline
\end{tabular}

Çizelge 2. Defne uçucu yağının Fusarium oxysporum f. sp. cepae, Macrophomina phaseolina, Rhizoctonia solani AG-4 ve Sclerotium rolfsii'nin miselyal gelişmesi üzerine toksisitesi

\begin{tabular}{cccc}
\hline \multirow{2}{*}{ Fungus } & \multicolumn{3}{c}{ Konsantrasyon $(\mu \mathrm{L} /$ petri) } \\
\cline { 2 - 4 } & $\mathrm{EC}_{50^{\mathrm{a}}}$ & $\mathrm{MIC}^{\mathrm{b}}$ & $\mathrm{MFC}^{\mathrm{c}}$ \\
\hline F. oxysporum f. sp. cepae & 9.84 & $>40$ & $>40$ \\
M. phaseolina & 5.28 & $>40$ & $>40$ \\
R. solani AG-4 & 3.55 & 20 & $>40$ \\
S. rolfsii & 2.74 & 20 & 40 \\
\hline
\end{tabular}

aMiselyal gelișimi 50\% oranında azaltan konsantrasyon.

bMinimum engelleyici konsantrasyon.

'Minimum fungisidal konsantrasyon. 
Çizelge 3. Defne uçucu yağının Fusarium oxysporum f. sp. cepae, Macrophomina phaseolina, Rhizoctonia solani AG-4 ve Sclerotium rolfsii'nin miselyal gelişmesi üzerine fungisidal ve fungistatik etkileri

\begin{tabular}{lccccc}
\hline \multirow{2}{*}{ Fungus } & \multicolumn{5}{c}{ Konsantrasyon $(\mu \mathrm{L} /$ petri) } \\
\cline { 2 - 6 } & $\begin{array}{c}2.5 \\
\text { gün }\end{array}$ & $\begin{array}{c}5 \\
\text { gün }\end{array}$ & $\begin{array}{c}10 \\
\text { gün }\end{array}$ & $\begin{array}{c}20 \\
\text { gün }\end{array}$ & $\begin{array}{c}40 \\
\text { gün }\end{array}$ \\
\hline F. oxysporum f. sp. cepae & ND* & ND & ND & ND & ND \\
M. phaseolina & ND & ND & ND & ND & ND \\
R. solani AG-4 & ND & ND & ND & 2 & 3 \\
S. rolfsii & ND & ND & ND & 2 & MFC \\
\hline
\end{tabular}

*ND = belirlenemedi

Defne yağının buhar etkisinin $F$. oxysporum f. sp. cepae'nın spor çimlenmesini 20 ve $40 \mu \mathrm{L} /$ petri konsantrasyonlarında sirasıyla \%14.25 ve 30.75 oranında azalttığını, ancak diğer üç konsantrasyon (2.5, 5 ve $10 \mu \mathrm{L} /$ petri)'un kontrolden farksız olduğu belirlenmiștir $(\mathrm{P}<0.05)$. Yağın 2.5 ve $5 \mu \mathrm{L} /$ petri konsantrasyonları $S$. rolfsii'nin sklerot çimlenmesini sirasiyla $\% 12.50$ ve 42.50 oranında azaltırken, 10 $\mu \mathrm{L} /$ petri ve üstü konsantrasyonlar sklerot çimlenmesini tamamen engellemiştir $(\mathrm{P}<0.05)$.

Yağ hidrosölünün $\% 5, \quad 10,20$ ve 40 konsantrasyonları $F$. oxysporum f. sp. cepae'nın spor çimlenmesini hiç etkilemezken, $S$. rolfsii'nin sklerot çimlenmesi çalışmada kullanılan en yüksek iki konsantrasyonda sirasiyla \%2.5 ve 7.5 oranında azaltmış ve bu istatiksel olarak kontrolden farklı bulunmuştur $(\mathrm{P}<0.05)$.

Toprak testi sonuçlarına göre defne yağının çalışmada kullanılan en yüksek konsantrasyon (40 $\mu \mathrm{L} /$ petri)' da hem $R$. solani AG-4 hem de $S$. rolfsii'yi tamamen engellediği, ancak $10 \mu \mathrm{L} /$ petri konsantrasyonda $S$. rolfsii'nin miselyal gelişimi \%93.46 oranında engellemesine karşın, bu oranın istatistiksel olarak yüksek konsantrasyonlarından farksız olduğu belirlenmiştir (Çizelge 4) $(\mathrm{P}<0.05)$. Yine benzer olarak M. phaseolina'nın miselyal gelişimi $40 \mu \mathrm{L} /$ petri konsantrasyonda \%95.53 oranında engellenmiş olmasına karșın, bu oran istatistiksel olarak yukarıdaki engellemelerden farksızdır $(\mathrm{P}<0.05)$. Halbuki $F$. oxysporum cepae'nın miselyal gelişimini en yüksek konsantrasyonda bile \%63.61 oranında engelleyebilmiștir.

Defne yağ hidrosölünün ise çalışmada kullanılan fungusların hiç birini tamamen engelleyemediği, ancak etkilerinin konsantrasyona bağlı olarak arttığı gözlenmiştir (Çizelge 5).
Çizelge 4. Toprak testinde defne uçucu yağının Fusarium oxysporum f. sp. cepae, Macrophomina phaseolina, Rhizoctonia solani AG-4 ve Sclerotium rolfsii'nin miselyal gelişmesi üzerine etkileri

\begin{tabular}{ccc}
\hline Fungus & Konsantrasyon $(\mu \mathrm{L} /$ petri) & Engelleme $(\%)$ \\
\hline \multirow{2}{*}{ F. } & 5 & $19.21 \mathrm{~h}^{\mathrm{a}}$ \\
oxysporum & 10 & $34.22 \mathrm{~g}$ \\
f. sp. cepae & 20 & $44.58 \mathrm{f}$ \\
\hline & 40 & $63.61 \mathrm{~d}$ \\
M. & 5 & $26.92 \mathrm{gh}$ \\
phaseolina & 10 & $48.46 \mathrm{ef}$ \\
& 20 & $72.68 \mathrm{c}$ \\
\hline \multirow{3}{*}{ solani } & 40 & $95.53 \mathrm{a}$ \\
AG-4 & 5 & $43.60 \mathrm{f}$ \\
& 10 & $63.10 \mathrm{~d}$ \\
& 20 & $86.15 \mathrm{~b}$ \\
S. rolfsii & 40 & $100.00 \mathrm{a}$ \\
& 5 & $54.66 \mathrm{e}$ \\
& 10 & $93.46 \mathrm{ab}$ \\
\hline
\end{tabular}

aAynı harfle gösterilen değerler arasında Tukey-HSD $\mathrm{P}<0.05$ 'e göre bir fark yoktur.

Çizelge 5. Toprak testinde defne yağ hidrosölünün Fusarium oxysporum f. sp. cepae, Macrophomina phaseolina, Rhizoctonia solani ve Sclerotium rolfsii'nin miselyal gelişmesi üzerine etkileri

\begin{tabular}{|c|c|c|}
\hline Fungus & $\begin{array}{c}\text { Konsantrasyon (\% } \\
\mathrm{w} / \mathrm{v})\end{array}$ & Engelleme (\%) \\
\hline \multirow{3}{*}{$\begin{array}{c}\text { F. oxysporum f. } \\
\text { sp. cepae }\end{array}$} & 10 & $-0.85 \mathrm{~d}^{\mathrm{a}}$ \\
\hline & 20 & $0.49 \mathrm{~d}$ \\
\hline & 40 & $2.91 \mathrm{~d}$ \\
\hline \multirow{3}{*}{ M. phaseolina } & 10 & $0.73 \mathrm{~d}$ \\
\hline & 20 & $2.39 \mathrm{~d}$ \\
\hline & 40 & $5.36 \mathrm{~cd}$ \\
\hline \multirow{3}{*}{ R. solani AG-4 } & 10 & $1.84 \mathrm{~d}$ \\
\hline & 20 & 11.18 \\
\hline & 40 & 26.80 \\
\hline \multirow{3}{*}{ S. rolfsi } & 10 & 10.51 \\
\hline & 20 & 20.44 \\
\hline & 40 & $35.13 \mathrm{a}$ \\
\hline
\end{tabular}

aAynı harfle gösterilen değerler arasında Tukey-HSD $\mathrm{P}<0.05$ e göre bir fark yoktur.

\section{Sonuçlar ve Tartışma}

Aromatik ve tıbbi bitkilerden elde edilen uçucu yağların, antibakteriyel, antifungal ve antioksidant özellikler gibi çeşitli biyolojik aktiviteye sahip oldukları çok eski çağlardan beri bilinmektedir (Baratta et al., 1998; Cosentino et al., 1999). Uçucu yağların biyolojik aktiviteleri, bitki genotipi ile belirlenen ve coğrafi köken, çevresel ve agronomik koşullar gibi çeşitli faktörlerden büyük ölçüde etkilenen kimyasal bileșimine bağlıdır (Giese, 1994; Rota et al., 2004; Yeşil Çeliktaş et al., 2007). Bitki uçucu yağları esas olarak terpenoidler ve diğer bazı 
düşük molekül ağırlıkta bileşikler (alifatik hidrokarbonlar, asitler, alkol, aldehitler, fenolik bileşikler, asiklik esterler veya laktonlar)'den oluşur (Rota et al., 2004). Uçucu yağların antimikrobiyal aktivitelerini bileşimi, yapısı ve ayrıca fonksiyonel gruplarında yer alan bu bileşikler belirler (Omidbeygi et al., 2007; Yeşil Çeliktaş et al., 2007). De Corato et al. (2010) süperkritik karbondioksit tekniği ile elde ettiği defne uçucu yağında 1,8-cineole (\%24.84), linalool (\%14.46), terpinil asetat (\%12.36) ve metil öjenol (\%10.09)'ü esas bileșenler olarak sınıflandırmışlardır. Mevcut çalışmada da GC/MS analizlerinde defne uçucu yağlarında 16 etken madde belirlenmiş olmasına karşın, bunlardan özellikle 1,8-cineole (\%57.03) ve terpinil asetat (\%13.35)'ın öne çıktığı belirlenmiştir.

Çalışmada defne uçucu yağ ve hidrosölünün $F$. oxysporum f. sp. cepae, M. phaeseolina, R. solani AG-4 ve $S$. rolfsii'ye karşı antifungal etkileri hem in vitro hem de toprak testleri ile araștırılmıștır. Ín vitro'da defne uçucu yağı $(40 \mu \mathrm{L} /$ petri $) R$. solani ve $S$. rolfsii'nin misel gelişmesini tamamen engellerken, diğer iki fungusa karşı engelleyici etkileri yüksek olmasına karşın tam engelleme gerçekleşmemiştir. Ayrıca defne uçucu yağının $40 \mu \mathrm{L} /$ petri konsantrasyonu $F$. oxysporum f. sp. cepae ve $M$. phaeseolina için fungistatik ve/veya fungisidal etkinlik göstermemesine karşın, $R$. solani AG-4 için fungistatik ve $S$. rolfsii için fungisidal etkinlikte olduğu gözlenmiştir. Diğer taraftan defne yă̆ hidrosölünün bu dört fungusa karşı etkileri çok daha düşük olup, herhangi bir fungitoksik etki belirlenememiştir. Önceki çalışmalarda mevcut sonuçlarla uyumlu olup, Müller-Riebau et al. (1995) defne yağının $1000 \mu \mathrm{L} / \mathrm{lt}$ konsantrasyonda $F$. moniforme, R. solani, Sclerotinia sclerotiorum ve Phytophthora capsici'nin miselyal gelişmelerini \%0.0-38.3 oranında engelleyebildiğini belirtmişlerdir. Defne uçucu yağlarının Aspergillus spp., Penicillium spp. ve Trichoderma viride'ye karşı fungitoksik özellik gösterdiği ve MIC ve MFC değerlerinin üç fungus için de sırasıyla $40 \mu \mathrm{L} / \mathrm{ml}$ ve $50 \mu \mathrm{L} / \mathrm{ml}$ olarak belirlenmiştir (Simic et al., 2004). Başka bir çalışmada adaçayından elde edilen hem 1,8 cineole hem de camphor uçucu yağlarının $F$. oxysporum f. sp. dianthi ve $F$. proliferatum'a karşı düșük bir engelleyici etki gösterirken, $R$. solani, $S$. sclerotiorum ve Fusarium solani f. sp. cucurbitae'ye karşı daha yüksek bir engelleyici etki gösterdiklerini, ancak her iki etken maddenin test edilen en yüksek konsantrasyon (500 $\mu \mathrm{L} / \mathrm{Lt})^{\prime} \mathrm{da}$ bile fungusların hiçbiri için fungistatik bir etki göstermediği rapor edilmiștir (Pitarokili et al., 2003). Türkölmez ve Soylu (2014) 1,8 cineole'ün $S$. rolfsii, $R$. solani ve $M$. phaseolina için üç farklı konsantrasyon (1500, 2010 ve $3000 \mu \mathrm{g} / \mathrm{mL}$ )'unun fungus misel gelişimini sırasıyla \%44.1, 81 ve 100 oranında azalttığını tespit etmişlerdir. Ayrıca aynı çalışmada kekik, rezene ve defne yağlarının uçucu fazlarının $S$. rolfsii, $R$. solani ve M. phaseolina'ya karşı antimikrobiyal aktiviteye sahip olduğu bildirilmiştir. Fusarium oxysporum f. sp. radicis-cucumerinum'un misel gelişimine karşı kekik, rezene, karabaş kekiği, defne ve yaban mersini uçucu yağlarının fungitoksik olduğu ve $\mathrm{EC}_{50}$ konsantrasyonlarının sırasıyla 0.013, 0.07, 0.20, 0.34 ve $0.6 \mathrm{mg} / \mathrm{mL}$ olduğu rapor edilmiștir (Soylu and İncekara, 2017). Boyraz and Özcan (2005) biberiye, kimyon, fesleğen, geyik otu ve sarı çörtük otlarının hidrosöllerinin çalıșmada kullandıkları en yüksek konsantrasyonda (\%15, v/v) Fusarium oxysporum f. sp. tulipae'nin misel gelişmesini \%18.82-89.41 arasında değişen oranlarda engelleyebildiğini, öte yandan geyik otu ve sarı çörtük otunun $R$. solani'nin misel gelişmesini tamamen engellerken, biberiye ve kimyonun sırasıyla \%7.8 ve \%39.64 oranında engelleyebildiğini, fakat fesleğenin hiçbir engelleyici etki göstermediğini rapor etmişlerdir.

Mevcut çalışmada, defne yağ $F$. oxysporum f. sp. cepae'nın spor çimlenmesini denemede kullanılan en yüksek konsantrasyonda bile nispeten azaltmasına karşın, daha düşük konsantrasyonlarda $S$. rolfsii'nin sklerot çimlenmesini tamamen engellemiştir. Ayrıca defne yağ hidrosölü spor çimlenmesini hiç etkilemezken, sklerot çimlenmesi üzerine çok sınırlı bir etkiye sahip olduğu belirlenmiştir. Daha önceki çalışmalarda, Soylu et al. (2006) Phytophthora infestans'a karşı kekik, lavanta, biberiye, rezene ve defne bitki uçucu yağlarının buhar fazının değme fazına oranla daha yüksek düzeyde etkinlik gösterdiğini ve fungusun sporangiumlarının çimlenmesini engellediğini bildirmişlerdir. Köse (2007) Alternaria alternata, Aspergillus niger, Botrytis cinerea ve Penicillium digitatum'un spor çimlenmesi üzerine bazı kekik çeşitleri (Ak kekik, Suriye kekiği, karabaş kekik), karabaş lavanta, rezene ve defne uçucu yağlarının buhar ve değme etkilerini araştırdığı çalışmada, defne uçucu yağının yağlar arasında funguslara karşı en düşük antifungal etkinliğe sahip olduğunu belirlemiştir. Aynı çalışmada defne uçucu yağının buhar etkinliği denemelerinde tüm fungusların spor çimlenmelerini sirasiyla $160,60,60$ ve $120 \mu \mathrm{g} / \mathrm{mL}$ 
konsantrasyolarda tamamen engellemesine karşın, aynı yağın değme etkinliği denemelerinde $A$. alternata ve $B$. cinerea'yı sirasiyla 2960 ve 3600 $\mu \mathrm{g} / \mathrm{mL}$ konsantrasyonda engellerken, $P$. digitatum ve A. niger sporlarının çimlenmesini çalışmada kullanılan en yüksek konsantrasyon (3920 $\mu \mathrm{g} / \mathrm{mL}$ )'da dahi tamamen engelleyemediği bildirilmiştir.

Çalışmada toprak testlerinde defne uçucu yağı $M$. phaeseolina, $R$. solani AG-4 ve $S$. rolfsii'nin miselyal gelişmelerini ya kuvvetli bir şekilde engellemiş ya da tamamen engellemiş, fakat çalışmada kullanılan en yüksek konsantrasyonda bile $F$. oxysporum f. sp. cepae'nın misel gelişimini tamamen durduramamıștır. Ayrıca defne yağ hidrosölü funguslar üzerine çok daha zayıf etkiler göstermișlerdir. Halbuki, geyik otunun yağ hidrosölünün $\quad \% 15^{\prime} l u ̈ k \quad$ konsantrasyonunun Alternaria mali ve B. cinerea'nın misel gelişimini tamamen engellediği rapor edilmiştir (Boyraz and Özcan, 2006). Soylu et al. (2007) origanum ve rezene uçucu yağlarının S. sclerotiorum'a karşı etkinliğinin in vitro ve in vivo koşullarda araștırdıkları bir çalışmada, bu yağların buhar fazının değme fazına oranla daha yüksek düzeyde etkinlik gösterdiği, dahası toprağa uygulanan uçucu yağların fungus hiflerinde oldukça önemli morfolojik bozulmalara neden olduğunu ve aynı zamanda fungus sklerotlarını da öldürdüğünü tespit etmişlerdir. Araştırıcılar ayrıca, uçucu yağın toprağa uygulanması ile hastalık çıkışının da \%53-70 oranında engellediğini belirlemişlerdir.

$\mathrm{Bu}$ çalışmada hem in vitro hem de toprak testlerinde defne uçucu yağının $F$. oxysporum f. sp. cepae, $M$. phaeseolina, $R$. solani AG-4 ve $S$. rolfsii'ye karşı defne yağ hidrosölünden daha etkili olduğu belirlenmiştir. Özellikle mücadelesi zor olan toprak kökenli patojenlere karşı sentetik fungusitlere alternatif olarak kullanılabilecek insan ve çevre sağlığ açısından güvenli olarak kabul edilen defne ve diğer bitkisel uçucu yağların etkinliklerinin daha detaylı araştırılması gerekir.

\section{Teşekkür}

$\mathrm{Bu}$ çalışma Ordu Üniversitesi Bilimsel Araștırma Projeleri tarafından desteklenmiştir (Proje No:AR1330).

\section{Kaynaklar}

Adams, R.P., 1995. Identification of Essential Oil Components by Gas Chromatography/Mass Spectroscopy. Allured Publishing Corporation Carol Stream, IL, USA, $469 \mathrm{p}$.

Agrios, G. N., 2005. Plant pathology, 5 th. edn. Elsevier Academic Press, San Diego, USA, 948 p.

Alaniz, S., Abad-Campos, P., García-Jiménez, J., Armengol, J., 2011. Evaluation of fungicides to control Cylindrocarpon liriodendri and Cylindrocarpon macrodidymum in vitro, and their effect during the rooting phase in the grapevine propagation process. Crop Protection, 30: 489-494.

Anonymous, 2018. Bitki koruma ürünleri veri tabanı programı. Available at https://bku.tarim.gov.tr. (Erişim tarihi: 11 Ekim 2018).

Arslan, Ü., İlhan, K., Vardar, C., Karabulut, Ö. A., 2009. Evaluation of antifungal activity of food additives against soilborne phytopathogenic fungi. World J Microbiol Biotechnol., 25: 537-543.

Baratta, M.T., Dorman, H.J.D., Deans, S.G., Figueiredo, A.C., Barroso, J.G., Ruberto, G., 1998. Antimicrobial and antioxidant properties of some commercial essential oils. Flavour and Fragrance Journal, 13: 235-244.

Bouchra, C., Achouri, M., Idrissi Hassani, L.M., Hmamouchi, M., 2003. Chemical Composition and Antifungal Activity of Essential Oils of Seven Moroccan Labiatae Against Botrytis cinera. Fr. Journal of Ethnopharmacology, 89: 165-169.

Bowers, J.H., Locke, J.C., 2004. Effect of Formulated Plant Extract and Oils on Population Density of Phytophthora nicotianae in Soil and Control of Phytophthora blight in the Greenhouse. Plant Disease, 88: 11-16.

Boyraz, N., Özcan, M., 2005. Antifungal effect of some spice hydrosols. Fitoterapia, 76: 661- 665.

Boyraz, N., Özcan, M., 2006. Inhibition of phytopathogenic fungi by essential oil, hydrosol, ground material and extract of summer savory (Satureja hortensis L.) growing wild in Turkey. International Journal of Food Microbiology, 107: 238-242.

Çakır, C., 1992. Antalya ve çevresinde doğal olarak yetişen bazı bitkilerin fungitoksik potansiyellerinin araştırılması. Yüksek Lisans Tezi, Akdeniz Üniversitesi, 91sayfa. 
Cosentino S., Tuberoso C.I.G., Pisano B., Satta M., Mascia V., Arzedi E., Palmas F., 1999. In vitro antimicrobial activity and chemical composition of Sardinian Thymus essential oils. Letters of Applied Microbiology, 29: 130-135.

Daferera, D.J., Ziogas, B.N., Polissiou, M.G., 2003. The Effectiveness of Plant Essential Oils on the Growth of Botrytis cinerea, Fusarium sp. and Clavibacter michiganensis subsp. michiganensis. Crop Protection, 22: 39-44.

De Corato, U., Maccioni, O., Trupo, and Di Sanzo, G., 2010. Use of essential oil of Laurus nobilis obtained by means of a supercritical carbondioxide technique against post harvest spoilage fungi. Crop Protection, 29: 142-147.

Duniway, J.M., 2002. Status of Chemical Alternatives to Methyl Bromide for Preplant Fumigation of Soil. Phytopathology, 92: 1337-1343.

Fan, C.M., Xiong, G.R., Qi, P., Ji, G.H., He, Y.Q., 2008. Potential biofumigation effects of Brassica oleracea var. caulorapa on growth of fungi. Journal of Phytopathology, 156:321-325.

Farih, A., Menge, J.A., Tsao, P.H., Ohr, H.D., 1981. Metalaxyl and efosite aluminum for control of Phytophthora gummosis and root rot on citrus. Plant Disease, 65: 654-657.

Giese, J., 1994. Spices and seasoning blends: A taste for all seasons. Food Technology, 48: 87-98.

Isman, B.M., 2000. Plant essential oils for pest and disease management. Crop Protection, 19: 603-608.

Köse, F., 2007. Turunçgillerde hasat sonrası patojenlere karşı bazı bitki uçucu yağlarının antifungal etkinliği. Y. Lisans Tezi, Mustafa Kemal Üniversitesi Fen Bilimleri Enstitüsü, Antakya/Hatay, 55s.

Lee, S.O., Choi, G.J., Jang, K.S., Lim, H.K., Cho, K.Y., Kim, J., 2007. Antifungal Activity of Five Plant Essential Oils as Fumigant Against Postharvest and Soilborne Plant Pathogenic Fungi. Plant Pathol. Journal, 23 (2): 97-102.

McLafferty, F.W., 1994. Wiley Registry of Mass Spectral Data. New York: Wiley.

Müller-Riebau, F., Berger, B., Yeğen, O., 1995. Chemical composition and Fungitoxic properties to phytopathogenic fungi of essential oils of selected aromatic plants growing wild in Turkey. J. Agric. Food Chem., 43: 2262-2266.

Omidbeygi, M., Barzegar M., Hamidi Z., Naghdibadi H., 2007. Antifungal activity of thyme, summer savory and clove essential oils against Aspergillus flavus in liquid medium and tomato paste. Food Control, 18: 1518-1523.
Paulitz, T.C., Belanger, R.R., 2001. Biological control in greenhouses systems. Annu. Rev. Phytopathol., 39: 103-133.

Pitarokili, D., Tzakou, O., Loukis, A. and Harvala, C., 2003. Volatile Metabolites from Salvia fruticosa as Antifungal Agents in Soilborne Pathogens. Journal of Agricultural and Food Chemistry, 51 (11): 3294 3301.

Ristic, M.D., Duletic-Lausavic, S., Knezevic-Vukcevic, J., Marin, P.D., Simic, D., Vukojevic, J., Janackovic, P., Vajs, V., 2000. Antimicrobial Activity of Essential Oils and Ethanol Extract of Phlomis fruticosa L. (Lamiaceae). Phytotherapy Research, 14: 267-271.

Rota, C., Carramiñana J.J., Burillo, J., Herrera, A., 2004. In vitro antimicrobial activity of essential oils from aromatic plants against selected foodborne pathogens. Journal of Food Protection, 67: 12521256.

Siddiqui, I.A., Shaukat, S.S., Khan, G.H., Zaki, M.J., 2002. Evaluation of Argemone mexicana for control of root-infecting fungi in tomato. Journal of Phytopathology, 150: 321-329.

Soylu, E.M., Tok, M.F., Soylu, S., Kaya, A.D., Evrendilek, G.A., 2005a. Antifungal Activities of the Essential Oil on Post-harvest Disease Agent Penicillium digitatum. Pakistan J. Biol Sci, 8: 25-29.

Soylu, E.M., YiğitbaG̦, H., Tok, M.F., Soylu, S., Baysal, O., Kaya, A.D., 2005b. Chemical Composition and Antifungal Activity of the Essential Oil of Artemisia annua L. Against Foliar and Soilborne Fungal Pathogens. Z. Pflanzenk Pflanze, 112: 229-239.

Soylu, E.M., Soylu, S., and Kurt, Ş., 2006. Antimicrobial activities of the essential oils of various plants against tomato late blight disease agent Phytophthora infestans. Mycopathologia, 161: 119128.

Soylu, S. Yigitbas, H., Soylu E.M. and Kurt, S., 2007. Antifungal effects of essential oils from oregano and fennel on Sclerotinia sclerotiorum. Journal of Applied Microbiology, 103: 1021-1030.

Soylu, E. M., İncekara, R., 2017. Biofungicidal activities of plant essential oils against cucumber root and stem rot disease caused by Fusarium oxysporum f. sp. radicis-cucumerinum. Journal of Plant Pathology, 99 (2): 437-444.

Thompson, D.P., 1989. Fungitoxic activity of essential oil components on food storage fungi. Mycologia, 81: 151-153.

Türkölmez, S., Soylu, E. M., 2014. Antifungal Efficacies of Plant Essential Oils and Main Constituents Against Soil-Borne Fungal Disease Agents of Bean. Journal of Essential Oil Bearing Plants, 17(2): 203-211. 
Tripathi, P., Dubey, N.K., Banerji, R., Chansouria, J.P.N., 2004. Evaluation of some essential oils as botanical fungi toxicants in management of post-harvest rotting of citrus fruits. World J Microbiol Biotechnol, 20: 317-321.

Walter, M., Jaspers, M.V., Eade, K., Frampton, C.M., Stewart, A., 2001. Control of Botrytis cinerea in Grape using Thyme Oil. Australasian Plant Pathology, 30: 21-25.

Wilson, C.L., Solar, J.M., El Ghaouth, A., Wisniewski, M.E., 1997. Rapid Evaluation of Extracts and Essential Oils for Antifungal Activity Against Botrytis cinerea. Plant Disease, 81: 204-210.

Yangui, T., Rhouma, A., Triki, M.A., Gargouri, K., Bouzid, J., 2008. Control of damping-off caused by Rhizoctonia solani and Fusarium solani using olive mill waste water and some of its indigenous bacterial strains. Crop Protection, 27: 189-197.

Yeșil Çeliktaş, O., Hames Kocabaş, E.E., Bedir, E., Vardar Sukan, F., Özek, T., Baser, K.H.C., 2007. Antimicrobial activities of methanol extracts and essential oils of Rosmarinus officinalis, depending on location and seasonal variations. Food Chemistry, 100: 553-559.

Yuen, G.Y., Schroth, M.N., Weinhold, A.R., Hancock, J.G., 1991. Effects of soil fumigation with methyl bromide and chloropicrin on root health and yield of strawberry. Plant Disease, 75: 416-420.

Zambonelli, A., Zechini D'aulerio, A., Bianchi, A., Albasin, A., 1996. Effects of Essential Oils on Phytopathogenic Fungi In vitro. Journal of Phytopathology, 144: 380383. 